needs are great. Rapid changes in patients' condition and the emotional and relationship changes this brings are hard, requiring constant adaptation and emotional resilience.

The 'Better Together Carers Programme' was developed in consultation with carers, as a structured weekly programme which aims to bring support and education to carers.

Each $2 \mathrm{~h}$ session is facilitated by two qualified, experienced Palliative Care Social Workers, to promote a safe and stable environment for carers to build relationships with each other and the facilitators.

The sessions offered:

- An informal 'check in' and 'check out' from all

- Guest speakers to give carers practical advice/signposting, and also tools to aid them in their caring role

- Simple complementary therapy massage and relaxation techniques

- Nutritional advice - for patient and carer

- Creative therapies

- Managing difficult and crisis situations

- Self care

- Social time with refreshments, allowing space to build relationships and peer support networks.

The final session took the form of a candlelit supper for both carer and cared for person; this provided a positive ending to the course and also affirmed the value of the carer's role.

Evaluation showed carers had gained greater confidence and skills in their caring role, had improved knowledge of resources available and had set up informal 'buddy' systems, which had improved their psychological well being. They valued the balance between information and emotionally charged discussion/ sharing and social time/checking in and out, which gave opportunity and permission to be light hearted and sociable. For them it made a real difference in being able to cope and we feel this to be an important model to share.

\section{P102 BETTER TOGETHER CARERS PROGRAMME}

Sandra Lawless, Briony Townshend Saint Francis Hospice, Essex, UK

10.1136/bmjspcare-2011-000105.102

Carers of palliative patients will often put their needs second to those for whom they are caring, but we know that their 